\title{
Glucose measure in arterial or in venous blood
}

\begin{abstract}
In current medical practice glycaemia is measured in blood collected from vein or capillaries.

In Intensive Care Units or during surgery, blood glucose is measured by $\mathrm{pH}$ meter from arterial catheters. Does a difference exist between the results of both measures? What might be its signification and consequences? The aim of this work was to give a beginning of answer to these questions.

Experiments conducted on 26 rats and analysis of 69 reports of Intensive Care Unit patients have shown that a significant difference in glycaemia depending on the origin of the collected blood (from arteries or from veins) may be observed mainly in pathological conditions or at the end of life.

Interpretation, possible explanations and consequences of this phenomenon are discussed and a hypothesis is proposed. The use of simultaneous double glucose determination in clinics is suggested.
\end{abstract}

Keywords: glucose metabolism, blood glucose measure, glycaemia, intensive care

\author{
Volume 6 Issue 5 - 2018
}

\section{Coulic V, ${ }^{1,3}$ Dobos S, ${ }^{1,2}$ Novikov V ${ }^{1,3}$}

'Free Brussels University Laboratory of Translational Research, Belgium

${ }^{2}$ Department of Abdominal, Thoracic and Laparoscopic Surgery, $\mathrm{CHU}$ Brugmann, Belgium

${ }^{3}$ VN Sklifosovskiy Scientific Research Institute of Emergency, Russia

Correspondence: Coulic Very, Laboratory of Translationa Research, 2, av. JJ Crocq, 1020 Brussels, Belgium Tel 322 4772574, 32 7I 364252, Email coulic.very@belgacom.net

Received: June 02, 2018 | Published: September 10, 2018
Abbreviations: ICU, intensive care unit; $\mathrm{Mg}$ /dl, milligram per decilitre; M, average value; N, Number; SD, standard deviation

\section{Introduction}

In current medical practice glycaemia is measured in blood collected from veins or capillaries.

In ICU or during surgery, blood glucose samples are often obtained from arterial catheters and glycaemia measured by $\mathrm{pH}$ meter. Does a significant difference exist between the values measured in these different conditions? And if there is one, what explanation may exist? What consequences might it have, taking into account the discussions about hyper- and hypoglycaemia in acute situations and their treatment. ${ }^{1-7}$

\section{Materials and methods}

Experiments were conducted on 26 Wistar and Fisher rats, 21 males and 5 females, body weight 292-400 g under Nembutal anaesthesia $\left(0.075 \mathrm{mg} / \mathrm{kg}\right.$ ). (Ethic Committee approbations $\mathrm{N}^{\circ} 414 \mathrm{~N}$ and $\left.606 \mathrm{~N}\right)$. In the first group (16 animals) only anaesthesia was performed and death was caused by anaesthetic drug overdose. In the second group (10 animals) after anaesthesia laparotomy was performed, ligatures were placed on ligamentum hepatoduodenale first (to avoid engorgement of the liver), then, on hepatic veins, in order to stop the outflow of the liver in direction of the heart. Blood collection was performed by puncture of the heart or section of the tail vein. The animal death was spontaneous or due to overdose of anaesthetics within 2-3 hours after the start of anaesthesia. The post mortem observation extended from 2 to 5 hours.

In ICU the dossiers of 84 patients hospitalised in USI during the period January-May 2016 were examined from the point of view of their glycaemia evaluation at the admission in ICU. Among them 69 were submitted to quasi simultaneous blood collection by puncture of the radial artery or venous catheters.
In rats glycaemia was determined once an hour by strips method only (glucometer One Touch, Switzerland or Accutrends, USA). In clinics, blood glucose was measured with the use of the "ADL-90 Flex" gasometer.

Taking into account the reliability of glucometers $( \pm 2 \%$ of the measured ciphers) we took in consideration as significant a difference no less than $5 \mathrm{mg} / \mathrm{dl}$ between the results of different measures when glycaemia $<200 \mathrm{mg} / \mathrm{dl}$, and no less than $10 \mathrm{mg} / \mathrm{dl}$ when glycaemia was $>200 \mathrm{mg} / \mathrm{dl}$.

Statistic evaluation was performed by Mean values \pm Standard Deviation calculation and Student criterion Td versus Tst was applied for determination of liability (p).

\section{Results}

In experiments on anaesthetized rats, considering each animal glucose measures at every moment, absence of difference between "venous" and "arterial" glycaemia was rather rare; 7,5\% before death, none after it (Table 1). In the majority of the cases arterial glycaemia was higher than venous one and this tendency increased with the observation delay (53.8\% frequency soon after anaesthesia, $83 \%$-before death, $91.3 \%$ after it). A venous glycaemia value higher than arterial one was observed in $23 \%$ of the cases soon after anaesthesia; in $8 \%$ within 1 hour and $0 \% 30$ min and later after death. Considering the mean values at consecutive observation moments the difference between arterial and venous glycaemia was not significant in the first hour after anaesthesia. Later the venous glycaemia had a tendency to diminish with time, especially after death (Figure 1).

Collecting of blood directly from the hepatic veins has shown a significant glycaemia increase relatively to values obtained in the "peripheral" venous blood, especially soon before and after death.

To verify the role of the liver in this phenomenon, the ligature of the liver veins was performed and, as shown in Table 2, the heart glycaemia has remained low. 


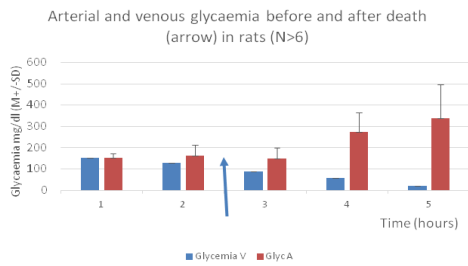

$<0.05$ immediately before death: $p<0.0$ I between arterial and venous glycaemia after death

Figure I "Arterial (red) and "venous" (blue) glycaemia in rats before and after death (arrow)

Abscissa: time in 30 minutes intervals;

Ordinate: glycaemia in $\mathrm{mg} / \mathrm{dl}$ ).

Table I Incidence of difference between glycaemia values in arterial and venous blood in ICU humans and in experiences on rats

\begin{tabular}{|c|c|c|c|c|c|c|}
\hline Series & Moment & Total Number/\% & $\begin{array}{l}\mathbf{A}=\mathbf{V} \\
\mathbf{N} / \%\end{array}$ & $\begin{array}{l}A>V \\
N \in . \%\end{array}$ & $\begin{array}{l}\mathbf{A}<\mathbf{V} \\
\mathbf{N} / \%\end{array}$ & $\begin{array}{l}\text { Total } \\
\text { differences }\end{array}$ \\
\hline \multirow{2}{*}{ RATS } & Before $\uparrow$ & $13 / 100$ & $1 / 7.5$ & $9 / 53.8$ & $3 / 23$ & $12 / 92.5$ \\
\hline & After $\dagger$ & $12 / 100$ & $0 / 0$ & $10 / 83$ & I/8.3 & $11 / 91.3$ \\
\hline HUMANS & Admission & $69 / 100$ & $32 / 48$ & $13 / 18.2$ & $24 / 34.8$ & $37 / 52$ \\
\hline
\end{tabular}

ICU Intensive Care Unit. †- death

Table 2 Measured differences between glycaemia values in arterial and venous blood in anaesthetized rats

\begin{tabular}{|c|c|c|c|c|}
\hline Series & $\begin{array}{l}\text { Tail vein Glycaemia } \\
\text { (Initial)-mg/dl }\end{array}$ & $\begin{array}{l}\text { Heart glycaemia } \\
\text { (initial)-mg/dl }\end{array}$ & $\begin{array}{l}\text { Tail vein glycaemia } \\
(†)-\mathrm{mg} / \mathrm{dl}\end{array}$ & $\begin{array}{l}\text { Heart glycaemia ( ( } \\
\dagger)-\mathrm{mg} / \mathrm{dl}\end{array}$ \\
\hline $\begin{array}{l}\text { Anaesthesia only } \\
N=10\end{array}$ & $152.3 \pm 13,0$ & $150.83 \pm 13$ & $73.3 \pm 28 *$ & $312 \pm 108 * *$ \\
\hline $\begin{array}{l}\text { LHD \& HV clamp } \\
N=10\end{array}$ & $|34| 1 \pm 14$. & $203 \pm 47 *$ & $81.6 \pm 64 *$ & $|48| \pm 84$. \\
\hline
\end{tabular}

$*_{p}<0.05$ relatively to tail vein glycaemia initial values, ${ }^{* *} \mathrm{p}<0.0$ I relatively to initial tail vein glycaemia

$\mathrm{N}$, number; LHD, hepatoduodenal ligamentum; HV, hepatic vein.

\section{Discussion}

In their work concerning glucose assimilation and turn over physiologists, mainly in animal experiments, have already shown that glucose levels are not the same depending from the vessels where the blood was obtained ${ }^{8,9}$ and others]. Diabetes specialists have always been aware of the difficulty of liable glycaemia evaluation and continue to improve their method of punctual or continuous recording glucose levels in blood or even in subcutaneous tissues. ${ }^{7,10-16}$ But the simultaneous registration of glucose levels in different places of the body is rather difficult to imagine in humans, except in ICU or surgery when it may be required.

Our data have confirmed that the results of simultaneous glycaemia determination could be different in values at different moments and conditions depending on the vessel which blood was collected from, either in experiments or in clinics.

In experiments our results has shown that in healthy anaesthetized rats at the beginning of the observation heart blood glycaemia (when it was measured) was the same as or a little higher than peripheral one. This seems logical, as far as the liver is considered as the main place of glucose stocking and neo genesis and liver blood outflow reaches directly the heart. Blood collecting from the hepatic veins has confirmed the hypothesis. ${ }^{8,9-17}$
It also seems logical that blood contents in peripheral veins may be lower than in arteriae, because blood has passed through organs and tissues which have utilized the glucose. So no difference or a mild difference between both kinds of values with eventual prevalence of arterial glycaemia could be a sign of the glucose metabolism equilibrium.

At the end of life caused by overdosing the anaesthetics-, venous glycaemia significantly diminished. This could be a sign either of increased needs of the organism, or of a decrease of glucose neo genesis and glycogen reserves. In the last case central glycaemia must be falling at the same time and this might be an alarm signal.

A second complementary explanation has to be considered. At the end of life, when blood circulation was failing, decreasing of the venous (peripheral) glycaemia was understandable due to blood supply decrease, but not the increase of the central one. Our results allow supposing the phenomenon linked with the beginning lysis of the hypoxic liver and the liberation of glucose from protein and other metabolite degradation. In these conditions clamping the hepatic veins ought to stop the increase of glucose contents in the heart blood. That was observed in the second group of experiments (Table 2). Such a brutal important increase of central glycaemia could be a sign of severe liver deficiency or even necrosis. 
The main consequence of these observations is the hypothesis that central/arterial glycaemia reflects the glucose amount accessible for the organism use, whereas peripheral/venous one represents the remaining free glucose after utilization by organs and tissues. In normal conditions the difference was minimal because of a quick mobilization of compensator mechanisms. Marked differences in the values of glucose contents in simultaneously collected central and peripheral blood could be an indication of more or less severe alterations of the glucose metabolism: either production or utilization of glucose or both, depending on the sign of the difference observed and on the absolute values obtained.

In clinics the observed tendencies were the same. Though a little less expressed, differences were detected in $52 \%$ of the critically ill patients and arterial glycaemia was low in 5 out the 6 pre mortem patients that give a beginning confirmation to the above mentioned hypothesis.

Nevertheless the recorded frequency of $A>V(18 \%)$ was twice less than $\mathrm{A}<\mathrm{V}(34 \%)$ that differs from experimental observations and may be due to the specific influence of the patients pathologies Taking into account the relatively limited number of observations and relatively high variety of pathologies present in ICU, the question could not be envisaged in the present study but remains a challenge for further investigations.

We can imagine different approaches of hyperglycaemia in these patients depending of the respective levels of central and peripheral glycaemia. Venous hyperglycaemia may be the consequence of different alterations of insulin production/utilization but also of other mechanisms and factors influencing the glucose metabolism. ${ }^{17,18}$ In such patients insulin administration would not be always pertinent: as already noted, observation of a too strict glycaemia regimen is known to be sometimes dangerous. ${ }^{3-6}$ The levels of central glycaemia and their evolution could be an indicator of the liver function as well, at least partly. For instance poor arterial glycaemia, or too high one, may be one of the markers indicating a liver insufficiency, respectively at its beginning when neo glycogenesis diminishes, or at its end, when lysis has begun. But the very causes of these organ or system pathologies leading to the observed glycaemia disturbances are still poorly known.

Anyway the simultaneous determination of central and peripheral blood glucose seems to be promising and deserves further investigations and studies for verification and possible development.

\section{Conclusion}

I. The differences between simultaneously recorded arterial (central) and venous (peripheral) glycaemia and their evolution probably reflect metabolic processes which we are not always aware of,

II. The presence of the absence of these differences can have an importance for understanding not only the physiology but also the disorders of glucose metabolism in different pathologies, as well as for a correct evaluation of the patient's condition

\section{Acknowledgements}

The authors are thankful to Professors P. Bergmann and F Corazza (Laboratory of Translational Research, ULB, Brussels), to Dr J.Devriendt (Intensive Care Unit of the CHU Brugmann, Brussels) and to Dr P Delrée (Institute of Pathology and Genetics, Gosselies,
Belgium) for their precious support, to M. A Bekkouri (LTM ULB? Brussels), Ms M Leroy (IPG, Gosselies) and J-L Kempeneers for their technical and logistic help.

\section{Conflict of interest}

The author declares there is no conflict of interest.

\section{References}

1. Van den Berghe G, Wouters P,Weekers F, et al. Intensive insulin therapy in critically ill patients. $N$ Engl J Med. 20018;345(19):1359-1367.

2. Van den Berghe G, Wilmer G, Hermans G, et al. Intensive insulin therapy in the medical ICU. $N$ Engl J Med. 2006;354(5):449-461.

3. Van den Berghe G, Wilmer G, Milants I, et al. Intensive insulin therapy in mixed medical/surgical intensive care units: good versus harm. Diabetes. 2006;55(11):3151-3159.

4. Thomann R, Keller U. Hyperglycémie dans les maladies aiguës-un risqué sucré. Forum médical Suisse. 2006 ;6:1051-1054.

5. Hirsch B. Understanding low sugar from NICE-SUGAR. N Engl J Med. 2012;367:1150-1152.

6. Kavanagh BP. (2012) Glucose in the ICU - Evidences, guidelines and outcomes. NEJM. 367:1259-60.

7. Kawahito K, Sato H, Kadosaki M, et al. Spike in glucose levels after reperfusion during aortic surgery: assessment by continuous blood glucose monitoring using artificial endocrine pancreas. Gen Thorac Cardiovasc Surg. Gen Thorac Cardiovasc Surg. 2018;66(3):150-154.

8. Hof J. Comparative studies on protein and blood sugar content of blood in heart and hepatic vein. Arztl Forschr. 1956;10(2):II/9-11.

9. Bergman EN, Katz ML, Kaufmann CF. Quantitative aspects of hepatic and portal glucose metabolism and turnover in sheep. Am J Physiol. 1970;219(3):785-793.

10. Buysschaert M, Lambotte L, reynaert M, et al. (1980) Use of an extracorporeal glucose monitor for the diagnosis and surgical treatment of an insulinoma. Br J Surg. 47(12):841-844.

11. Guéniot M. Assay methods for glycaemia; problem interpretation. Nouv Presse Méd. 1980;9(14):1025-1027.

12. Colas C, Slama G. Rapid control of glycaemia with reactive sticks. A comparison study of 5 methods. Nouv Presse Med. 10(32):2631-2634.

13. Faure P. Méthodes d'étude du glucose en pathologie; Etude de santé Med@Tice, Faculkté de Médecine et de Pharmacie de Grenoble.

14. Farmer TG, Edgar TG, Peppas NA. The future of open and closedloop insulin delivery for Diabetes Mellitus. J Pharm Pharmacol. 2008;60(1):1-13.

15. Matsuda E, Brennan P. The effectiveness of continuous subcutaneous insulin pumps with continuous glucose monitoring in outpatient adolescents with type 1 diabetes: a systematic review. JBI Libr Syst Rev. 2012;10(42 Suppl):1-10.

16. Sparacino G, Zanon M, Facchinetti A, et al. Italian contribution to the development of continuous glucose monitoring sensors for diabetes management. Sensors (Basel). 2012;12(10):13753-13780.

17. Adeva-Andany MM, Perez-Felpete N, Fernandez-Fernandez C, et al. Liver glucose metabolism in human. Biosci Rep. 2016;36(6).

18. Panza-Nduli J, Coulic V, Willems D, et al. Influence of bedside insulin measurement on acute coronary syndrome pathways. Crit Pathw Cardiol. 2011;10(4):185-188. 